\title{
Recyclable Porous Glass-Ceramics from the Smelting of MSWI Bottom Ash
}

\author{
Patricia Rabelo Monich ${ }^{1}$, Hugo Lucas ${ }^{2}$, Bernd Friedrich ${ }^{2}$ (D) and Enrico Bernardo ${ }^{1, *(D)}$ \\ 1 Dipartimento di Ingegneria Industriale, Università degli Studi di Padova, Via Marzolo 9, 35131 Padova, Italy; \\ patricia.rabelomonich@unipd.it \\ 2 IME Process Metallurgy and Metal Recycling, RWTH Aachen University, 52056 Aachen, Germany; \\ hlucas@metallurgie.rwth-aachen.de (H.L.); bfriedrich@metallurgie.rwth-aachen.de (B.F.) \\ * Correspondence: enrico.bernardo@unipd.it.com
}

\section{check for} updates

Citation: Rabelo Monich, P.; Lucas, H.; Friedrich, B.; Bernardo, E. Recyclable Porous Glass-Ceramics from the Smelting of MSWI Bottom Ash. Ceramics 2021, 4 , 1-11. https://doi.org/ceramics4010001

Received: 4 October 2020

Accepted: 14 December 2020

Published: 29 December 2020

Publisher's Note: MDPI stays neutral with regard to jurisdictional claims in published maps and institutional affiliations.

Copyright: () 2020 by the authors. Licensee MDPI, Basel, Switzerland. This article is an open access article distributed under the terms and conditions of the Creative Commons Attribution (CC BY) license (https: / / creativecommons.org/ licenses/by/4.0/).

\begin{abstract}
Material from the electric arc furnace smelting of municipal solid waste incineration (MSWI) bottom ash was easily converted into highly porous glass-ceramics by a combination of inorganic gel casting and sinter-crystallization at $1000^{\circ} \mathrm{C}$. In particular, the gelation of aqueous suspensions of fine glass powders, transformed into "green" foams by intensive mechanical stirring, occurred with a limited addition of alkali activator $(1 \mathrm{M} \mathrm{NaOH})$. The products coupled the stabilization of pollutants with good mechanical properties (e.g., compressive strength approaching $4 \mathrm{MPa}$ ). Interestingly, they could be used also as raw material for new glass-ceramic foams, obtained by the same gel casting and sintering method, with no degradation of chemical stability. Limitations in the crushing strength, derived from the limited viscous flow densification of semi-crystalline powders, were overcome by mixing powders from recycled foams with $30 \mathrm{wt} \%$ soda-lime glass. The new products finally featured an even higher strength-to-density ratio than the foams from the first cycle.
\end{abstract}

Keywords: porous glass-ceramics; vitrified bottom ash; alkali activation; sinter-crystallization; permanent materials

\section{Introduction}

A milestone in the circular economy is undoubtedly represented by the concept of "end of waste" [1]. A certain waste stream can be conveniently used for energy generation, exploiting the organic fraction, subjected to combustion (direct generation) [2] or thermochemical conversion (indirect generation, by the synthesis of new fuels) [3] but, in general, its "pollution potential" does not disappear. In fact, inorganic fractions remain as a fundamental by-product, with even enhanced hazardousness, due to the concentration of noxious compounds [4]. A genuinely circular approach cannot neglect the treatment of the by-products, by transformation into safe and useful products.

Bottom ash from MSW incineration is included among inorganic waste in which vitrification is suggested, in order to stabilize the pollutants [5,6]. Vitrified residues can be safely disposed in landfills or employed by themselves as aggregates [6]. However, since vitrification implies a substantial energy consumption, the process can be economically and environmentally sustainable only if the vitrified residue is further valorized into high-added value products, including glass-based foams for thermal and acoustic insulation $[7,8]$. Compared to polymer-based insulators, glass-derived foams offer a higher mechanical strength and thermo-chemical stability (in particular, inorganic foams are not flammable) [7,9]. They may be completely amorphous (as in the case of already commercially established products (e.g., under the trade names of Foamglas ${ }^{\circledR}$ and Misapor ${ }^{\circledR}$ ) $[7,9]$ or semi-crystalline (glass-ceramic foams) [9].

A modern alternative to waste vitrification is represented by the development of "inorganic polymers" [10]. Inorganic polymers can be defined as the products of the dissolution of solid silica- and alumina-rich starting materials in highly concentrated alkali 
solutions, followed by gelation-according to the condensation of corrosion products (hydrated silica- and alumina-based compounds), at nearly room temperatures. Excellent mechanical properties and chemical stability are achieved especially when forming "zeolite-like" gels [11,12], i.e., configuring the subgroup of inorganic polymers known as "geopolymers". Zeolite-like gels feature a three-dimensional network structure, resulting from the bridging of $\mathrm{SiO}_{4}$ and $\mathrm{AlO}_{4}$ tetrahedral units, from the dissolution of starting materials, with alkali ions-from the activating solution-trapped in the interstitial spaces and stabilizing the tetrahedral coordination of $\mathrm{Al}$ ions [12]. It is evident that the formation of a zeolite-like gel corresponds to quite well defined proportions between silica, alumina, and alkali oxides, which are generally obtained by the use, as alkaline activators, of synthetic alkali silicates and aluminates, rather than simple sodium or potassium hydroxides. In addition, a substantial dissolution of starting materials is obtained by only operating at high molarity of alkaline compounds (e.g., $\mathrm{NaOH}$ or $\mathrm{KOH}>>3 \mathrm{M}$ ) [13].

The paper aims at presenting a different strategy, comprising waste vitrification, alkali activation, and valorization of waste in the form of inorganic foams. The sustainability of vitrification is encouraged passing from a "melting" approach to a "smelting" one: The process, in other words, is not implemented as autonomous, but integrated with metal extraction, by means of an electric arc furnace. The sustainability of alkali activation is improved by the use of simply sodium hydroxide, at low molarity (e.g., $\mathrm{NaOH}$ or $\mathrm{KOH}<3 \mathrm{M}$ ) and foams are still considered as a target product, by a gel casting approach-followed by firing at moderate temperatures [14] — not involving expensive additives (such as $\mathrm{SiC}$ ) [9]. In particular, after the partial dissolution in alkaline solution, suspensions of fine glass powders are known to undergo hardening due to the formation of gel-forming compounds (e.g., hydrated calcium silicates or hydrated alkali carbonates) [14]. The "gelled" slurries are later easily foamed by vigorous mechanical stirring with the support of a surfactant. Once the stirring stops, the collapse of the bubbles is avoided due to the pseudoplasticity of the gels. The foamed suspension is then poured into a mold and dried. The porous structure is finally subjected to viscous flow sintering [14-16].

The novelty of this study concerns, first, the application of the latter "inorganic gel casting" approach to the vitrified material from bottom ash smelting, using an alkali activator at a particularly low molarity $(1 \mathrm{M} \mathrm{NaOH})$. Second, the recyclability potential of the obtained waste-derived glass-ceramic foams was also considered. The manufacturing of durable products from waste-derived glass does not strictly represent a "permanent" solution, since nothing can be said about the same products in the end-of-life condition. It will be demonstrated, however, that the approach is so flexible to be applicable even to powders from crushed foams, especially by the addition of recycled soda-lime glass. Foams of the second production cycle were found to exhibit an even improved strength-todensity ratio and no degradation of the chemical stability.

\section{Materials and Methods}

MSWI bottom ash (BA) was kindly supplied by the company AVR (Veendam, The Netherlands) and dried at $200{ }^{\circ} \mathrm{C}$ for $24 \mathrm{~h}$. The metal content was assessed by mechanical separation (magnetic separation and eddy current separation), whereas the non-metallic fraction was studied by means of thermogravimetry (DSC/TG, 3+ STARe System, Mettler Toledo, Columbus, OH, USA) and X-ray fluorescence spectroscopy (Panalytical WDXRF spectrometer (Malvern Panalytical B.V., Eindhoven, The Netherlands). The chemical composition is shown in Table 1.

The as received BA (with no metal separation), after drying, was added to a graphite crucible and smelted in a lab-scale submerged arc furnace (SAF) at around $1450-1550{ }^{\circ} \mathrm{C}$. The molten slag ash was subsequently quenched in water, dried, and ground below $75 \mu \mathrm{m}$, by ball milling. The chemical composition of the obtained vitrified bottom ash (again assessed by means of X-ray fluorescence spectroscopy) is also shown in Table 1. The thermal evolution of the material was studied by means of differential scanning calorimetry 
(DSC/TG, 3+ STARe System, Mettler Toledo, Columbus, OH, USA), operating with a heating rate of $10^{\circ} \mathrm{C} / \mathrm{min}$, on fine powders.

Table 1. Bulk composition of recycled soda-lime glass, bottom ash, and smelting outputs.

\begin{tabular}{|c|c|c|c|c|}
\hline Oxide $(w t \%)$ & Soda-Lime Glass (SLG) & Bottom Ash (BA) * & Vitrified BA (VBA) & $\begin{array}{l}\text { Air Pollution Control } \\
\text { Residues (APCR) }\end{array}$ \\
\hline $\mathrm{SiO}_{2}$ & 71.9 & 40.1 & 48.1 & 25.0 \\
\hline $\mathrm{Al}_{2} \mathrm{O}_{3}$ & 1.2 & 9.6 & 18.2 & 10.7 \\
\hline $\mathrm{CaO}$ & 7.5 & 19.8 & 20.0 & 21.3 \\
\hline $\mathrm{Na}_{2} \mathrm{O}$ & 14.3 & 4.8 & 4.7 & 8.4 \\
\hline $\mathrm{MgO}$ & 4 & 2.2 & 2.5 & 1.9 \\
\hline $\mathrm{K}_{2} \mathrm{O}$ & 0.4 & 1.0 & 0.8 & 1.4 \\
\hline $\mathrm{Fe}_{2} \mathrm{O}_{3}$ & & 10.4 & 1.1 & 7.9 \\
\hline $\mathrm{TiO}_{2}$ & 0.1 & 1.2 & 1.0 & 1.3 \\
\hline $\mathrm{MnO}$ & & 0.1 & 0.6 & 0.2 \\
\hline $\mathrm{P}_{2} \mathrm{O}_{5}$ & & 1.3 & 0.1 & 2.0 \\
\hline $\mathrm{ZnO}$ & & 0.7 & 0.0 & 8.1 \\
\hline $\mathrm{PbO}$ & & 0.2 & 0.0 & 1.1 \\
\hline $\mathrm{Cr}_{2} \mathrm{O}_{3}$ & & 0.2 & 0.0 & 0.2 \\
\hline $\mathrm{BaO}$ & & 0.2 & 0.2 & 0.1 \\
\hline $\mathrm{CuO}$ & & 0.7 & 0.3 & 1.9 \\
\hline $\mathrm{SO} 3$ & & 2.0 & 1.5 & 3.8 \\
\hline $\mathrm{Cl}$ & & 1.3 & 0.1 & 3.3 \\
\hline C & & 4.0 & 0.6 & 0.1 \\
\hline
\end{tabular}

* BA contains between 8 to $10 \mathrm{wt} \%$ of metal particles, which are not included in this chemical composition.

Porous glass-ceramics were developed by firstly mixing at $400 \mathrm{rpm}$ fine powders of vitrified bottom ash to an alkaline solution of $1 \mathrm{M} \mathrm{NaOH}$. The overall solid content corresponded to $70 \mathrm{wt} \%$ of the suspension. After $3 \mathrm{~h}$ of partial dissolution of the glass, $4 \mathrm{wt} \%$ of the surfactant (Triton X-100 (polyoxyethylene octyl phenyl ether- $-\mathrm{C}_{14} \mathrm{H}_{22} \mathrm{O}\left(\mathrm{C}_{2} \mathrm{H}_{4} \mathrm{O}\right)_{\mathrm{n}}$, $\mathrm{n}=9-10$, Sigma-Aldrich, Gillingham, UK) was added to the suspension, which could be easily foamed by intensive mechanical stirring at $2000 \mathrm{rpm}$. Thereafter, the foamed slurry was transferred to a rectangular mold and dried at $40^{\circ} \mathrm{C}$. After $48 \mathrm{~h}$ of drying, the sample was demolded and fired at $1000{ }^{\circ} \mathrm{C}$, with a heating rate of $10^{\circ} \mathrm{C} / \mathrm{min}$ and a holding time of $1 \mathrm{~h}$.

"Recycled foams" were first developed by crushing and dry ball milling the fired porous glass-ceramics. The ground powder was then sieved below $75 \mu \mathrm{m}$ and subjected to the same process described for vitrified bottom ash glass-ceramic foams $(1 \mathrm{M} \mathrm{NaOH}$ alkali activation followed by foaming, curing, and firing at $1000{ }^{\circ} \mathrm{C}$ ). Foams made with mixing recycled material with $30 \mathrm{wt} \%$ recycled soda-lime glass were also developed ("recycled VBA/SLG" foams). The glass additive, already presenting a medium particle size of $30 \mu \mathrm{m}$, was kindly provided by SASIL SpA (Brusnengo, Biella, Italy). This fraction of soda-lime glass actually constituted an additional waste material, since it cannot be applied in the production of glass, due to the presence of ceramic contaminations [14]. Table 1 contains also the chemical composition of the adopted soda-lime glass.

Fourier-transform infrared spectra were recorded with Jasco 4200 FTIR spectrometer (Jasco, Japan) equipped with an attenuated total reflection (ATR) attachment (ZnSe crystal) on fine powders. Each spectrum was measured by conducting 32 scans at a resolution of $4 \mathrm{~cm}^{-1}$, from 700 to $4000 \mathrm{~cm}^{-1}$.

X-ray diffraction (XRD) (Bruker D8 Advance, Karlsruhe, Germany) was performed on fine powders employing $\mathrm{CuK} \alpha$ radiation, $0.15418 \mathrm{~nm}, 40 \mathrm{kV}-40 \mathrm{~mA}, 2 \theta=10-70^{\circ}$, step size of $0.02^{\circ}$, in order to conduct the mineralogical characterization. In addition, phase identification was done by means of the semi-automatic Match! ${ }^{\circledR}$ program package (Crystal Impact GbR, Bonn, Germany), supported by data from the Powder Diffraction File (PDF)-2 database (International Centre for Diffraction Data, Newtown Square, PA, USA). 
Optical stereomicroscopy (AxioCam ERc 5 s Microscope Camera, Carl Zeiss Microscopy, Thornwood, NY, USA) and scanning electron microscopy (FEI Quanta 200 ESEM, Eindhoven, The Netherlands) were employed for morphological and microstructural characterizations of the samples.

The glass-ceramic foams were cut into cubes of about $10 \times 10 \times 10 \mathrm{~mm}$, which were employed for density measurements and compressive tests. The geometric density ( $\left.\rho_{\text {geom}}\right)$ of samples was computed from the weight-to-volume ratios on regular blocks (cut from bigger foamed samples), after careful determinations of weights and dimensions by means of an analytical balance and a digital caliper. The apparent density $\left(\rho_{\text {apparent }}\right)$ and the true density ( $\rho_{\text {true }}$ ) were evaluated by means of a helium pycnometer (Micromeritics AccuPyc 1330, Norcross, GA, USA), operating on bulk or on finely crushed samples, respectively. The measured density values were employed to calculate the amount of total, open, and closed porosity. The compressive test was performed at room temperature on at least nine samples from each group, by means of an Instron 1121 UTM (Instron, Norwood, MA, USA), operating with a cross-head speed of $1 \mathrm{~mm} / \mathrm{min}$.

The leaching tests were conducted on finely crushed samples, following norm EN 12457-4 [17]. The solid fragments and pure distilled water (liquid/solid ratio of 10) were added to a plastic flask, which was mixed for $24 \mathrm{~h}$ at room temperature. The suspension was then filtered and centrifuged. The heavy metals content of the eluate were measured by inductively coupled plasma (ICP; SPECTRO Analytical instruments GmbH, Kleve, Germany) and further compared to the limit values allowed for waste acceptable at landfills for inert waste [18].

\section{Results and Discussion}

\subsection{Vitrification of Bottom Ash}

Bottom ash is known to correspond to a quite complex mixture of mineral compounds and metals [19]. As shown in Figure 1, the adopted ash contained iron oxides (hematite, $\mathrm{Fe}_{2} \mathrm{O}_{3}, \mathrm{PDF} \# 33-0664$, and magnetite, $\left.\mathrm{Fe}_{3} \mathrm{O}_{4}, \mathrm{PDF} 72-2303\right)$, quartz ( $\left.\mathrm{SiO}_{2}, \mathrm{PDF} \# 83-0539\right)$, rutile $\left(\mathrm{TiO}_{2}, \mathrm{PDF} \# 21-1276\right)$, calcium carbonate (calcite, $\left.\mathrm{CaCO}_{3}, \mathrm{PDF} \# 72-1214\right)$, anhydrous calcium sulphate (anhydrite, $\mathrm{CaSO}_{4}, \mathrm{PDF} 37-1496$ ), and aluminum (Al, PDF\#89-4037). The total amount of metal traces (8-10 $\mathrm{wt} \%$ ) was estimated by means of mechanical separation. Finally, the ash contained "organic carbon", i.e., carbon from organic residues, in an amount of $4 \mathrm{wt} \%$ (assessed by means of thermogravimetry).

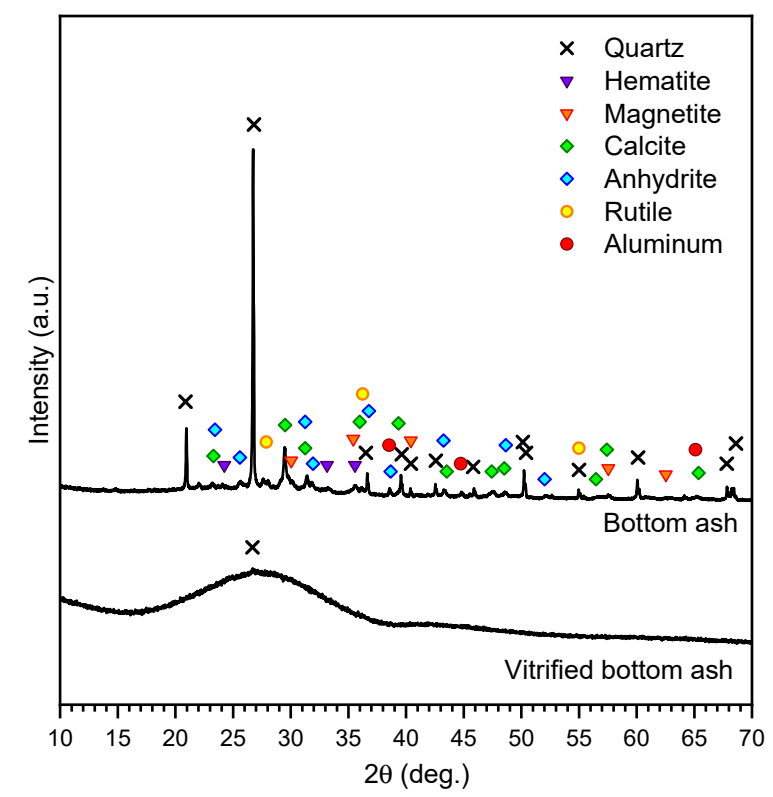

Figure 1. XRD patterns of bottom ash before and after smelting. 
The smelting determined the reaction between the constituents. The organic carbon, together with Al particles, in fact, play a crucial role in the reduction of metal oxides, such as $\mathrm{Fe}, \mathrm{Cu}$, or Zn oxides. Chemical compositions of BA and VBA in Table 1 clearly show how the proportion of $\mathrm{Al}_{2} \mathrm{O}_{3}$ increases during vitrification while carbon and $\mathrm{Fe}_{2} \mathrm{O}_{3}$ decrease substantially.

During the smelting, 3 to $5 \mathrm{wt} \%$ of BA left the system through the exhaust gases as air pollution control residues (APCR), having a $\mathrm{CaO}-\mathrm{Al}_{2} \mathrm{O}_{3}-\mathrm{SiO}_{2}$ matrix. In general, chlorides, $\mathrm{Na}$, and heavy metals, such as $\mathrm{Pb}$ or $\mathrm{Zn}$, tend to leave during the smelting at $1500{ }^{\circ} \mathrm{C}$ (Table 1-APCR). The rest of the metals, such as Fe, $\mathrm{Cu}, \mathrm{Cr}, \mathrm{Mo}$, or Ni, formed a metallic phase at the bottom of the crucible, recovered at the end of the process.

Pre-existent metals, i.e., $\mathrm{Fe}, \mathrm{Cu}, \mathrm{Cr}, \mathrm{Ni}$, and fractions derived from the reduction of metal oxides coagulate at the bottom of the crucible. The metal alloy formed represented approximately $10 \mathrm{wt} \%$ of the original BA, as reported in Table 2. It contained 9-12 $\mathrm{wt} \%$ of $\mathrm{Cu}$ but also traces of highly valuable $\mathrm{Nb}, \mathrm{Nd}$, and $\mathrm{Ag}$. These metals were particularly interesting, since their extraction from bottom ash, e.g., by mechanical separation, is not efficient. It should be noted that iron and copper, from a Fe-Cu alloy, may be separated by an additional smelting step (selective oxidation smelting) [20].

Table 2. Chemical composition of the metal output of bottom ash (BA) smelting.

\begin{tabular}{ccccccccc}
\hline $\begin{array}{c}\text { Element } \\
(\mathbf{w t} \%)\end{array}$ & $\mathbf{F e}$ & $\mathbf{C u}$ & $\mathbf{S i}$ & $\mathbf{P}$ & $\mathbf{C r}$ & $\mathbf{N i}$ & $\mathbf{C o}$ & $\mathbf{S n}$ \\
\hline Average & 80.3 & 10.8 & 1.9 & 1.4 & 1.1 & 0.6 & 0.4 & 0.2 \\
Error & 3.0 & 1.9 & 0.4 & 0.6 & 0.3 & 0.2 & 0.2 & 0.03 \\
Trace & $\mathbf{M o}$ & $\mathbf{S b}$ & $\mathbf{Z n}$ & $\mathbf{B i}$ & $\mathbf{N b}$ & $\mathbf{A g}$ & $\mathbf{N d}$ & $\mathbf{C d}$ \\
$\begin{array}{c}\text { Elements } \\
\text { ppm }\end{array}$ & $250-1550$ & $700-1200$ & $100-490$ & $170-350$ & $5-90$ & $25-80$ & $15-20$ & $5-9$ \\
\hline
\end{tabular}

As illustrated in Figure 1, the inorganic residue of BA smelting was fully amorphous, except for weak quartz traces. In addition, as shown in Table 1, the chemical composition did not simply correspond to the removal of heavy metal oxides. The $\mathrm{Al}_{2} \mathrm{O}_{3}$ content, in particular, changed substantially before and after smelting, as an effect of both concentrations of several minerals after the release of $25 \mathrm{wt} \%$ volatiles and oxidation of $\mathrm{Al}$ particles at a high temperature.

\subsection{Vitrified Bottom Ash-Based Porous Glass-Ceramics}

According to the DSC curve in Figure 2, vitrified bottom ash-sieved below $75 \mu \mathrm{m}-$ exhibited a crystallization exothermic peak $\left(\mathrm{T}_{\mathrm{C}}\right)$ at $940{ }^{\circ} \mathrm{C}$. A slight excess in the firing temperature $\left(1000{ }^{\circ} \mathrm{C}\right)$, compared to $\mathrm{T}_{\mathrm{c}}$, was set in order to achieve simultaneously a significant crystallization and a good densification, by viscous flow sintering, of the starting glass powders.

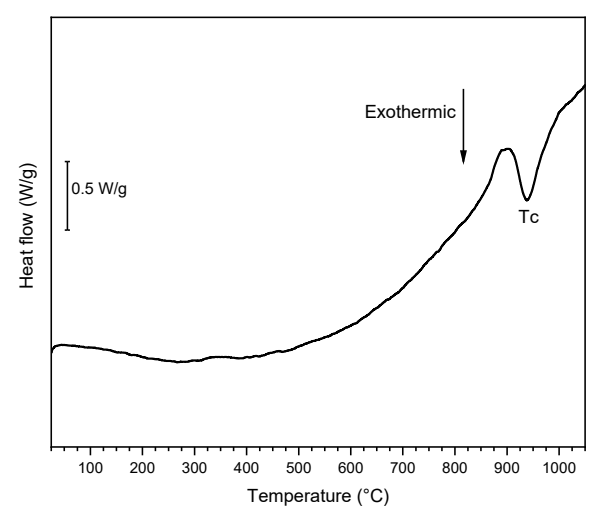

Figure 2. DSC curve of fine vitrified bottom ash powder. 
Figure 3a clearly illustrates the obtainment of highly porous bodies after the low temperature foaming and hardening of suspension of vitrified bottom ash powders. The opencelled morphology, as shown in Figure 3b, was preserved after firing at $1000{ }^{\circ} \mathrm{C}$ : the formation of crystal inclusions, in softened glass, evidently prevented any viscous collapse of the cellular structure.
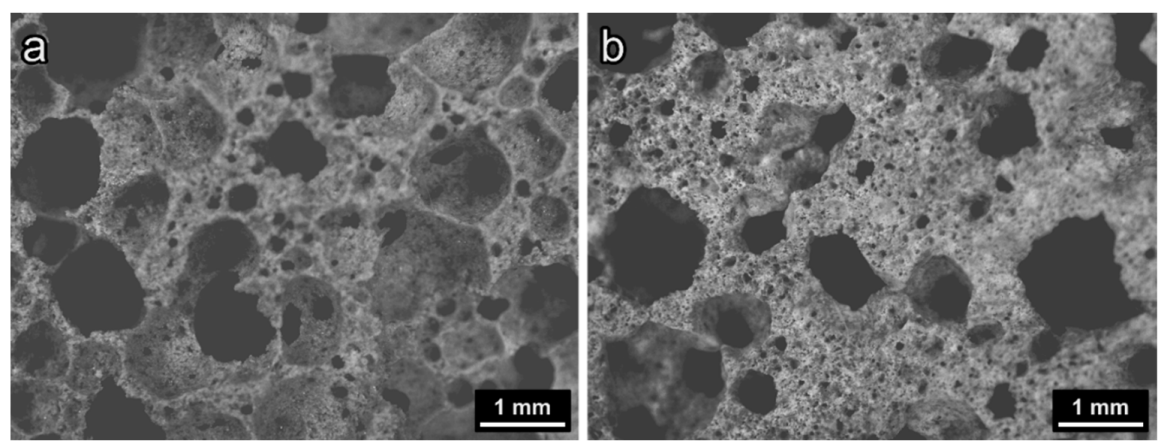

Figure 3. Microstructure of the porous glass-ceramics made with vitrified bottom ash: (a) "Green" foam; (b) fired foam.

The transformations occurring upon gelation and firing were monitored by means of both infrared spectroscopy and mineralogical analysis (Figure 4). Vitrified bottom ash in the as received state (i.e., as resulting from the smelting process), in the FTIR spectrum (bottom plot in Figure 4a), exhibited only a band corresponding to the asymmetric Si-O-Si stretching vibration [21]. In contrast, the alkali activation (central plot in Figure 4a) led to the appearance of a band between 1530 and $1370 \mathrm{~cm}^{-1}$ associated to the stretching vibration of the $\mathrm{C}-\mathrm{O}$ bond [22]. The limited signals at $\sim 3500 \mathrm{~cm}^{-1}(\mathrm{O}-\mathrm{H}$ stretching) and at $\sim 1700 \mathrm{~cm}^{-1}$ (O-H bending) suggested the formation of a hydrated carbonate phase, rather than hydrated calcium silicate compounds (formed with soda-lime glass [14]), in analogy with previous studies concerning a more intense alkali activation (up to $2.5 \mathrm{M}$ $\mathrm{NaOH}$ ) of fine glass powders from direct bottom ash vitrification [15]. Finally, the band situated between 3030 and $2750 \mathrm{~cm}^{-1}$ was attributed to the $\mathrm{C}-\mathrm{H}_{2}$ stretching from surfactant Triton X-100 [14]. The disappearance of the $\mathrm{C}-\mathrm{O}$ and $\mathrm{C}-\mathrm{H}_{2}$ bands, with firing (top plot in Figure $4 a$ ), was consistent with the decomposition of both the newly formed carbonate phase and organic additive.
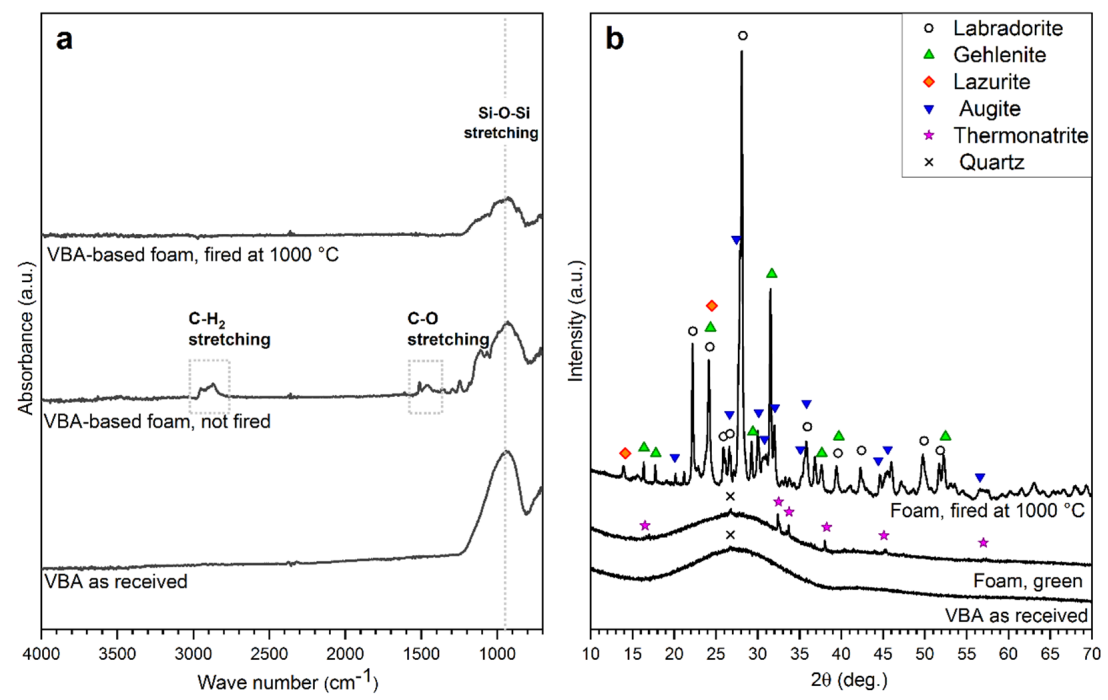

Figure 4. FTIR spectra (a) and XRD patterns (b) of vitrified BA (VBA) as received and VBA-based foams before and after firing at $1000{ }^{\circ} \mathrm{C}$. 
Figure $4 \mathrm{~b}$ exhibits the mineralogical analysis of vitrified bottom ash, before and after transformations. The weak diffraction peaks in the "green" foam were effectively consistent with the formation of a carbonate phase, namely thermonatrite $\left(\mathrm{Na}_{2} \mathrm{CO}_{3} \cdot \mathrm{H} 2 \mathrm{O}, \mathrm{PDF} \# 00\right.$ 008-0448). Figure $3 \mathrm{~b}$ also reveals that the firing treatment performed at $1000{ }^{\circ} \mathrm{C}$ led to the precipitation of labradorite $\left(\left(\mathrm{Ca}_{0.64} \mathrm{Na}_{0.35}\left(\mathrm{Al}_{1.63} \mathrm{Si}_{2.37} \mathrm{O}_{8}\right), \mathrm{PDF} \# 83-1371\right)\right.$ and gehlenite $\left(\mathrm{Ca}_{2} \mathrm{Al}_{2} \mathrm{SiO}_{7}, \mathrm{PDF} \# 74-1607\right)$. Traces of augite $\left(\mathrm{CaMg}_{0.7} \mathrm{Al}_{0.6} \mathrm{Si}_{1.7} \mathrm{O}_{6}, \mathrm{PDF} 78-1392\right)$ and lazurite $\left(\mathrm{Na}_{8.56}\left(\mathrm{Al}_{6} \mathrm{Si}_{6} \mathrm{O}_{24}\right)\left(\mathrm{SO}_{4}\right)_{1.56} \mathrm{~S}_{.44}\right.$, PDF\#77-1702) were also detected.

Although not as remarkable as in the case of foams from directly vitrified bottom ash [15], the strength-to-density ratio of the fired foams $\left(\sigma_{\text {comp }} / \rho_{\text {geom }}=5 \mathrm{MPa} \cdot \mathrm{cm}^{3} / \mathrm{g}\right)$ was consistent with the development of a strong, crystallized solid phase. This could be understood by applying the well-known Gibson and Ashby's model for open-celled foams $[7,23]$. According to this model, the crushing strength derives from the bending strength of the solid phase $\left(\sigma_{\text {bend }}\right)$, "downscaled" by porosity (expressed by the relative density, in turn defined as $\rho_{\text {rel }}=1$-total porosity), as follows:

$$
\sigma_{\text {comp }}=\sigma_{\text {bend }} \cdot\left[0.2 \cdot\left(\rho_{\text {rel }}\right)^{1.5}\right] \rightarrow \sigma_{\text {bend }}=\sigma_{\text {comp }} /\left[0.2 \cdot\left(\rho_{\text {rel }}\right)^{1.5}\right]
$$

The calculated value for the bending strength, obtained by reversing Gibson and Ashby's equation and introducing the experimental values of crushing strength $\left(\sigma_{\text {comp }}=\sim 4 \mathrm{MPa}\right)$ and porosity (72\%), well exceeded $120 \mathrm{MPa}$ (see Table 3 ), in agreement with the typical bending strength of dense waste-derived glass-ceramics of a similar composition (e.g., slag sitals, developed in the former USSR starting from the 1960s) [24].

Table 3. Mechanical and physical properties of the glass-ceramic foams.

\begin{tabular}{cccc}
\hline Group of Samples & VBA-Based Foam & Recycled Foam & $\begin{array}{c}\text { 70\% Recycled } \\
\text { Foam/30\% SLG }\end{array}$ \\
\hline$\rho_{\text {geom }}\left(\mathrm{g} / \mathrm{cm}^{3}\right)$ & Density Determinations & $0.66 \pm 0.00$ \\
$\rho_{\text {apparent }}\left(\mathrm{g} / \mathrm{cm}^{3}\right)$ & $0.76 \pm 0.03$ & $2.66 \pm 0.03$ & $2.59 \pm 0.01$ \\
$\rho_{\text {true }}\left(\mathrm{g} / \mathrm{cm}^{3}\right)$ & $2.45 \pm 0.00$ & $2.72 \pm 0.00$ & $2.63 \pm 0.00$ \\
& $2.70 \pm 0.00$ & Porosity Distribution & 74.8 \\
Total porosity $(\mathrm{vol} \%)$ & 71.9 & 75 & 74.5 \\
Open porosity $(\mathrm{vol} \%)$ & 68.9 & 74.4 & 0.3 \\
Closed porosity $(\mathrm{vol} \%)$ & 2.9 & 0.6 & $4.9 \pm 1.2$ \\
$\sigma_{\text {comp }}(\mathrm{MPa})$ & Strength Determinations & $1.0 \pm 0.1$ & 196.4 \\
\hline
\end{tabular}

** Calculated according to Gibson and Ashby's model for open-celled foams [23].

Before any possible commercial exploitation of waste-derived products, an assessment of the environmental impact is paramount. Leaching tests (Table 4) indicate a good stabilization of heavy metals after firing of vitrified bottom ash-based foams. According to the leachate values of the metal ions analyzed, the foams could be classified as inert [18]. Therefore, these results suggested that crystallization did not affect the chemical stability of the glass and that the pollutants were effectively immobilized in the crystals or in the residual glassy phases.

\section{3. "Recycled" Porous Glass-Ceramics}

In order to explore the circularity of the proposed method, powders from the crushing of previous glass-ceramic foams ("recycled" powders) were considered as new raw materials, subjected to activation by immersion in the $\mathrm{NaOH}$ solution, pure or mixed with fine powders of soda-lime glass (30 wt\%). The new tests were conducted in analogy with recent experiments on the application of gel casting/sintering approach to semi-crystalline powders, instead on fully amorphous powders [25]. 
Table 4. Results of the leaching test of the developed porous glass-ceramics $(\mathrm{mg} / \mathrm{kg})$.

\begin{tabular}{|c|c|c|c|c|c|c|}
\hline Element & $\begin{array}{l}\text { Limit Values } \\
\text { for Inert Waste }\end{array}$ & $\begin{array}{c}\text { BA } \\
\text { before Smelting }\end{array}$ & VBA & VBA-Based Foam & Recycled Foam & $\begin{array}{c}70 \% \text { Recycled } \\
\text { Foam } / 30 \% \text { SLG }\end{array}$ \\
\hline As & 0.5 & 0.03 & 0.01 & 0.06 & 0.11 & 0.15 \\
\hline $\mathrm{Ba}$ & 20 & 1.42 & 0.24 & 0.16 & 0.95 & 1.09 \\
\hline $\mathrm{Cd}$ & 0.04 & $<0.01$ & $<0.01$ & $<0.01$ & $<0.01$ & $<0.01$ \\
\hline $\mathrm{Cr}$ & 0.5 & 0.02 & 0.07 & $<0.01$ & 0.51 & 0.46 \\
\hline $\mathrm{Cu}$ & 2 & 3.64 & 0.08 & 0.14 & 0.76 & 0.13 \\
\hline Mo & 0.5 & 1.14 & 0.4 & 0.05 & 0.03 & 0.03 \\
\hline $\mathrm{Ni}$ & 0.4 & 0.16 & $<0.01$ & $<0.01$ & $<0.01$ & $<0.01$ \\
\hline $\mathrm{Pb}$ & 0.5 & $<0.01$ & 0.14 & 0.05 & 0.05 & $<0.01$ \\
\hline $\mathrm{Zn}$ & 4 & $<0.01$ & 0.05 & 0.20 & 0.20 & 0.20 \\
\hline
\end{tabular}

As shown in Figure 5a,d, the process was confirmed in leading to highly porous "green" foams, independently from the addition of soda-lime glass. The mineralogical analysis of the new foams in the green state (Figure 6a) did not reveal the formation of any extra crystalline compound, with activation. The intensity of diffraction peaks, with the addition of soda-lime glass, naturally decreased according to the introduction of the extra amorphous material.

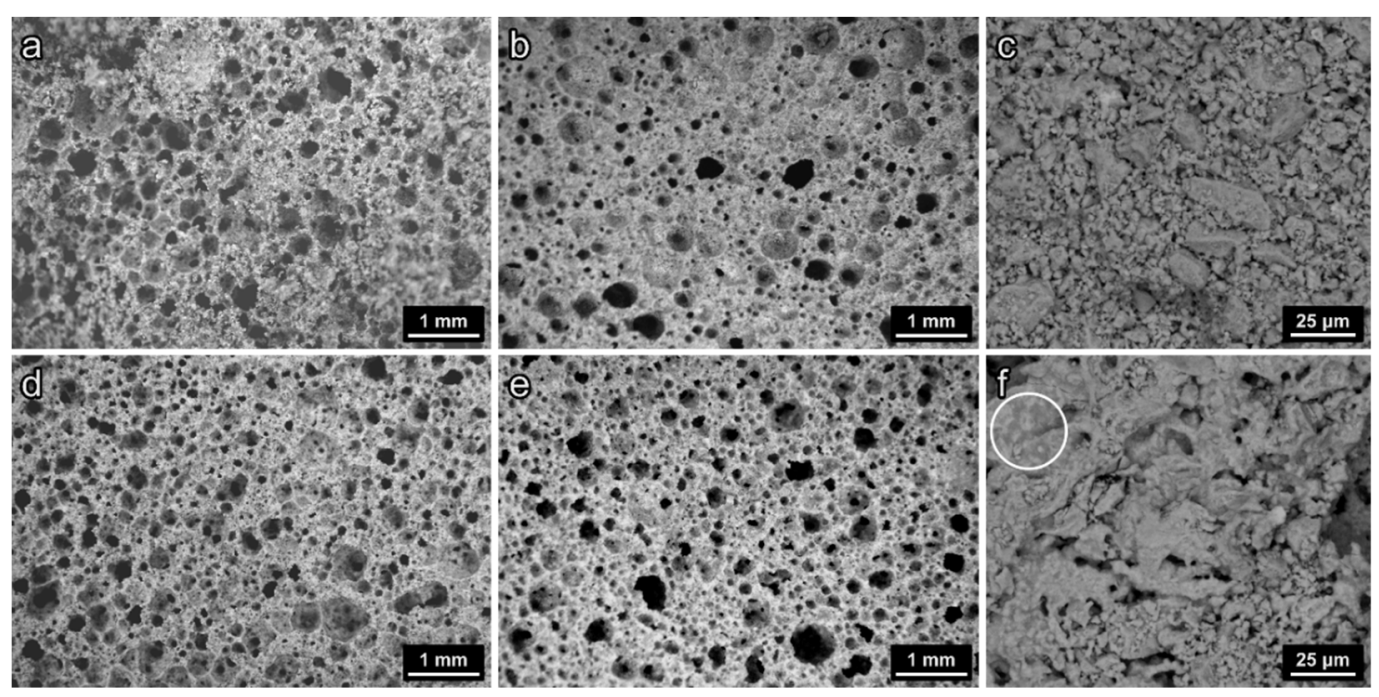

Figure 5. Microstructural details of recycled VBA-based materials: (a) "Pure" recycled foams, not fired; $(\mathbf{b}, \mathbf{c})$ "pure" recycled foams, fired; $(\mathbf{d})$ recycled VBA/soda-lime glass (SLG) foams, not fired; $(\mathbf{e}, \mathbf{f})$ recycled VBA/SLG foams, fired.

The overall cellular structure of the green foams was preserved upon firing at $1000{ }^{\circ} \mathrm{C}$, as exhibited in Figure 5b,e. Both recycled foams kept an abundant porosity (75 vol\%), again mainly open, as reported in Table 3.

Unlike morphology, the mechanical properties were greatly affected by the recycling process. In the case of recycled foam made without soda-lime glass, the calculated bending strength had a dramatic decrease. This could be justified by the higher magnification details shown in Figure 5c,f. The residual glass phase, left after the first firing, sufficed for the alkali activation, but it could not determine a good densification of cell struts, upon the second firing. Powders exhibited just some necking (Figure 5c). On the contrary, soda-lime glass could offer a substantial viscous flow and "glue" the glass-ceramic particles from the first firing cycle (Figure 5f; see, in particular, the zone marked by a circle). The resulting foams exhibited an even enhanced strength-to-density ratio, more precisely, the new foams, with a $\sigma_{\text {comp }} / \rho_{\text {geom }}$ ratio of $7.4 \mathrm{MPa} \cdot \mathrm{cm}^{3} / \mathrm{g}$, compared well with foams both from the first cycle. 

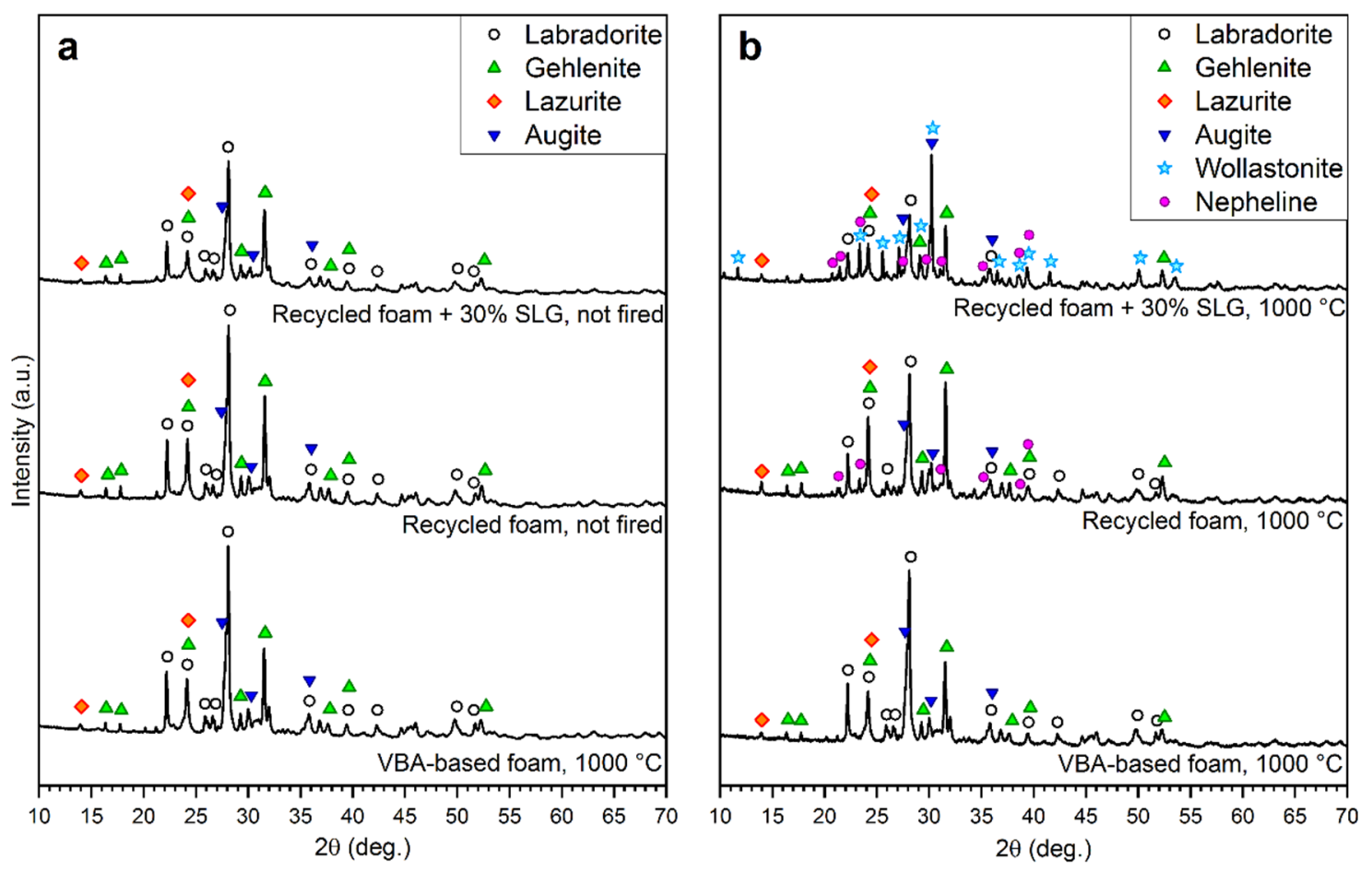

Figure 6. X-ray diffraction patterns of vitrified bottom ash-based foams after firing and after recycling with or without the addition of soda-lime glass: (a) "green"; (b) fired.

In all cases, the reactivation actually led to "reactive" sintering, i.e., the glass-ceramic powders from the first firing underwent transformations not only due to the addition of soda-lime glass, but also to the same alkali intake from the activating solution. As shown in Figure $6 \mathrm{~b}$, the reheating of previously fired vitrified bottom ash reduced the content of labradorite. With no glass added, this was accompanied by a promotion of gehlenite and appearance of nepheline $\left(\mathrm{Na}_{7.11}\left(\mathrm{Al}_{7.2} \mathrm{Si}_{8.8} \mathrm{O}_{32}\right)\right.$, PDF\#79-0991). In the case of recycled VBA/SLG, the interaction of fine powders of soda-lime glass and fired vitrified bottom ash during the thermal treatment determined a pronounced precipitation of wollastonite $\left(\mathrm{CaSiO}_{3}, \mathrm{PDF} 84-0655\right)$, coupled with more intense nepheline traces.

The "decomposition" of gehlenite to form wollastonite is already known. Zhang and Liu [26], as an example, produced wollastonite-based glass-ceramics by mixing soda-lime glass with a "crystallization promoter" (derived from the firing of kaolin clay, $\mathrm{CaCO}_{3}$, $\mathrm{BaCO}_{3}$, and $\mathrm{ZnO}$ ) based on the same gehlenite. Aluminum ions diffused from gehlenite towards the softened glass due to the compositional gradient (high alumina content in gehlenite, low alumina content in soda-lime glass). A similar effect had been observed with a glass-ceramic powder including crystals of gehlenite-akermanite solid solution, reacting with soda-lime glass and leading to wollastonite and diopside (Ca-Mg silicate) [25].

The reduction of labradorite, i.e., a calcium-sodium feldspar, likely occurred by the specific action of sodium ions from the activating solution and soda-lime glass, on the feldspar structure. Anorthite, i.e., calcium feldspar $\left(\mathrm{CaAl}_{2} \mathrm{Si}_{2} \mathrm{O}_{8}\right)$, may transform into nepheline by replacing any $\mathrm{Ca}^{2+}$ ion with two $\mathrm{Na}^{+}$ions, according to a reaction with the negative Gibbs energy, specifically active at $1000{ }^{\circ} \mathrm{C}$, according to Wang et al. [27]:

$$
\mathrm{Na}_{2} \mathrm{O}+\mathrm{CaAl}_{2} \mathrm{Si}_{2} \mathrm{O}_{8} \text { (anorthite) } \rightarrow 2 \mathrm{NaAlSiO}_{4} \text { (nepheline) }+\mathrm{CaO}
$$

The release of $\mathrm{Ca}^{2+}$ could in turn trigger the observed increase of gehlenite (without soda-lime glass) and formation of wollastonite (with soda-lime glass).

Despite the mineralogical transformations (and consequent changes in the chemical composition of the solid phase), the chemical stability was preserved (see Table 4). The leachate values were in general lower for the original foams. Nonetheless, for the metal 
ions analyzed, both recycled foams (made with or without the addition of soda-lime glass) were below the threshold values for inert waste. The only exception was $\mathrm{Cr}$, which reached the limit value for this class of waste. It should be noted, however, that the attacked foam sample, due to its low density and high porosity, featured a huge specific surface, so that the leaching test can be considered as extremely severe.

In conclusion, the results from this study indicate that porous glass-ceramics made by vitrified bottom ash could be potentially applied as safe building materials, such as panels for acoustic and thermal insulation, given the high porosity. At the end of life, these panels could be fully recovered, crushed, and combined with soda-lime glass, in the production of new foams, thus configuring "permanent" materials (e.g., materials enabling further recycling after being dismantled) [28].

The glass addition may be seen as a fundamental design tool for obtaining products with constant or even improved properties. The variability of chemical compositions of bottom ash (which could degrade the properties) may be compensated not only a prioriby mixing bottom ash with minerals and/or other inorganic waste-but also a posteriori, by adjusting the soda-lime glass content. Future investigations will specifically deal with extensions of the overall approach to new batches.

\section{Conclusions}

We may conclude that:

- Treating MSWI BA through SAF favors the generation of an amorphous mineral precursor, which represents around $65-68 \mathrm{wt} \%$ of BA and a rich Fe-Cu metal phase, in an amount of 9-12 $\mathrm{wt} \%$. The cleaning of the starting waste and the extraction of valuable metals are the main benefits of the thermal treatment. In fact, the separation yields a vitreous slag, to be transformed into useful products, and a metal alloy, which may undergo further separation steps;

- The vitreous slag from BA smelting could be easily transformed into highly porous glass-ceramics, according to the mechanical foaming of suspensions of fine powders, undergoing gelation in alkaline aqueous solutions, followed by sintering;

- For the sake of sustainability, the gelation could be achieved with limited molarity of the alkali activator $(1 \mathrm{M} \mathrm{NaOH})$; firing, in addition, could be conducted at a moderate temperature, $1000^{\circ} \mathrm{C}$, with significant crystallization-in turn promoting the obtainment of glass-ceramic foams with a good strength-to-density ratio-coupled with an excellent stabilization of pollutants;

- The glass-ceramic foams were tested as raw material for a second manufacturing cycle. Although still successful in the stabilization of pollutants, the "recycling" approach was not acceptable for the low strength of the products;

- The stabilization of pollutants and the strength of foams from the second cycle could be optimized by the addition of $30 \mathrm{wt} \%$ soda-lime glass, in a condition of reactive sintering, implying an extensive transformation of the phase assemblage;

- The gel casting/sintering approach, applied to the waste-derived material, possibly combined with soda-lime glass, has a great potential for permanent waste minimization.

Author Contributions: For this paper, P.R.M. performed the general experimentation, except the smelting of MSWI bottom ash, which was done by H.L.; E.B. and B.F. supervised the experiments; E.B. and P.R.M. wrote and edited the article. All authors have read and agreed to the published version of the manuscript.

Funding: This research was funded by the European Union's Horizon 2020 research and innovation programme, under the Marie Skłodowska-Curie, grant agreement no. 721185 “NEW-MINE” (EU Training Network for Resource Recovery through Enhanced Landfill Mining; website: http: //new-mine.eu/).

Acknowledgments: The authors thank SASIL S.p.a. (Brusnengo, Biella, Italy) for the supply of soda-lime glass. The authors would also like to thank Giulia Zanmarchi for the ICP analysis and Sirio Galletto for the DSC analysis. 
Conflicts of Interest: The authors declare no conflict of interest.

\section{References}

1. Ragossnig, A.M.; Schneider, D.R. Circular economy, recycling and end-of-waste. Waste Manag. Res. 2019, 37, 109-111. [CrossRef] [PubMed]

2. Cucchiella, F.; D'Adamo, I.; Gastaldi, M. Strategic municipal solid waste management: A quantitative model for Italian regions. Energy Convers. Manag. 2014, 77, 709-720. [CrossRef]

3. Shahbaz, M.; Yusup, S.; Inayat, A.; Patrick, D.O.; Ammar, M. The influence of catalysts in biomass steam gasification and catalytic potential of coal bottom ash in biomass steam gasification: A review. Renew. Sustain. Energy Rev. 2017, 73, 468-476. [CrossRef]

4. Saveyn, H.; Eder, P.; Garbarino, E.; Muchova, L.; Hjelmar, O.; van der Sloot, H.; Comans, R.; van Zomeren, A.; Hyks, J.; Oberender, A Study on Methodological Aspects Regarding Limit Values for Pollutants in Aggregates in the Context of the Possible Development of End-of-Waste Criteria Under the EU Waste Framework Directive; Publications Office of the European Union: Luxembourg, 2014.

5. Xiao, Y.; Oorsprong, M.; Yang, Y.; Voncken, J.H.L. Vitrification of bottom ash from a municipal solid waste incinerator. Waste Manag. 2008, 28, 1020-1026. [CrossRef] [PubMed]

6. Colombo, P.; Brusatin, G.; Bernardo, E.; Scarinci, G. Inertization and reuse of waste materials by vitrification and fabrication of glass-based products. Curr. Opin. Solid State Mater. Sci. 2003, 7, 225-239. [CrossRef]

7. Rincón, A.; Marangoni, M.; Cetin, S.; Bernardo, E. Recycling of inorganic waste in monolithic and cellular glass-based materials for structural and functional applications. J. Chem. Technol. Biotechnol. 2016, 91, 1946-1961. [CrossRef] [PubMed]

8. Rawlings, R.D.; Wu, J.P.; Boccaccini, A.R. Glass-ceramics: Their production from wastes-A Review. J. Mater. Sci. 2006, 41, 733-761. [CrossRef]

9. Scarinci, G.; Brusatin, G.; Bernardo, E. Glass Foams. In Cellular Ceramics: Structure, Manufacturing, Properties and Applications, 1st ed.; Scheffler, M., Colombo, P., Eds.; Wiley-VCH Verlag GmbH \& Co. KGaA: Weinheim, Germany, $2005 ;$ pp. 158-176.

10. Silva, R.V.; de Brito, J.; Lynn, C.J.; Dhir, R.K. Use of municipal solid waste incineration bottom ashes in alkali-activated materials, ceramics and granular applications: A review. Waste Manag. 2017, 68, 207-220. [CrossRef]

11. Provis, J.L. Geopolymers and other alkali activated materials: Why, how, and what? Mater. Struct. 2014, 47, 11-25. [CrossRef]

12. Lancellotti, I.; Kamseu, E.; Michelazzi, M.; Barbieri, L.; Corradi, A.; Leonelli, C. Chemical stability of geopolymers containing municipal solid waste incinerator fly ash. Waste Manag. 2010, 30, 673-679. [CrossRef]

13. Idir, R.; Cyr, M.; Pavoine, A. Investigations on the durability of alkali-activated recycled glass. Constr. Build. Mater. 2020, $236,117477$. [CrossRef]

14. Rincón, A.; Giacomello, G.; Pasetto, M.; Bernardo, E. Novel 'inorganic gel casting' process for the manufacturing of glass foams. J. Eur. Ceram. Soc. 2017, 37, 2227-2234. [CrossRef]

15. Rincon Romero, A.; Salvo, M.; Bernardo, E. Up-cycling of vitrified bottom ash from MSWI into glass-ceramic foams by means of 'inorganic gel casting' and sinter-crystallization. Constr. Build. Mater. 2018, 192, 133-140. [CrossRef]

16. Rabelo Monich, P.; Dogrul, F.; Lucas, H.; Friedrich, B.; Bernardo, E. Strong porous glass-ceramics from alkali activation and sinter-crystallization of vitrified MSWI bottom ash. Detritus 2019, 08, 101-108. [CrossRef]

17. BS EN 12457-4:2002. Characterisation of Waste. Leaching. Compliance Test for Leaching of Granular Waste Materials and Sludges. One Stage Batch Test at a Liquid to Solid Ratio of $10 \mathrm{~L} / \mathrm{kg}$ for Materials with Particle Size below $10 \mathrm{~mm}$ (without or with Size Reduction); BS EN: London, UK, 2002.

18. Directive 2003/33/EC, 2003. Official Journal of the European Communities. 2003. L 11/27. Available online: https: / eur-lex.europa. eu/LexUriServ/LexUriServ.do?uri=OJ:L:2003:011:0027:0049:EN:PDF (accessed on 29 December 2020).

19. Šyc, M.; Simon, F.G.; Hykš, J.; Braga, R.; Biganzoli, L.; Costa, G.; Funari, V.; Grosso, M. Metal recovery from incineration bottom ash: State-of-the-art and recent developments. J. Haz. Mat. 2020, 393. [CrossRef]

20. Zheng, Y.X.; Lv, J.F.; Lai, Z.N.; Lan, Z.Y.; Wang, H. Innovative methodology for separating copper and iron from Fe-Cu alloy residues by selective oxidation smelting. J. Clean. Prod. 2019, 231, 110-120. [CrossRef]

21. Pisciella, P.; Crisucci, S.; Karamanov, A.; Pelino, M. Chemical durability of glasses obtained by vitrification of industrial wastes. Waste Manag. 2001, 21, 1-9. [CrossRef]

22. Nedeljković, M.; Ghiassi, B.; Melzer, S.; Kooij, C.; van der Laan, S.; Ye, G. $\mathrm{CO}_{2}$ binding capacity of alkali-activated fly ash and slag pastes. Ceram. Int. 2018, 44, 19646-19660. [CrossRef]

23. Gibson, L.J.; Ashby, M.F. Cellular Solids: Structure and Properties, 2nd ed.; Cambridge University Press: Cambridge, UK, 2014; pp. 1-510.

24. Höland, W.; Beall, G.H. Glass-Ceramic Technology, 2nd ed.; John Wiley \& Sons, Inc.: Hoboken, NJ, USA, $2012 ;$ pp. $123-126$.

25. Rabelo Monich, P.; Romero, A.R.; Rambaldi, E.; Bernardo, E. Case studies of up-cycling of partially crystallized ceramic waste in highly porous glass-ceramics. Constr. Build. Mater. 2020, 261, 119971. [CrossRef]

26. Zhang, W.; Liu, H. A low cost route for fabrication of wollastonite glass-ceramics directly using soda-lime waste glass by reactive crystallization-sintering. Ceram. Int. 2013, 39, 1943-1949. [CrossRef]

27. Wang, Y.; Wang, D.; Dong, C.; Yang, Y. The behaviour and reactions of sodium containing minerals in ash melting process. J. Energy Inst. 2017, 90, 167-173. [CrossRef]

28. Grosso, M.; Niero, M.; Rigamonti, L. Circular economy, permanent materials and limitations to recycling: Where do we stand and what is the way forward? Waste Manag. Res. 2017, 35, 793-794. [CrossRef] 